\title{
A militarização das escolas públicas sob os enfoques de três direitos: constitucional, educacional e administrativo
}

\author{
The militarization of public schools from the perspective of three rights: \\ constitutional, educational and administrative \\ La militarización de las escuelas públicas bajo la perspectiva de tres derechos: \\ constitucional, educativo y administrativo \\ SALOMÃO BARROS XIMENES \\ CAROLINA GABAS STUCHI \\ MÁRCIO ALAN MENEZES MOREIRA
}

\begin{abstract}
Resumo: $O$ artigo apresenta um ensaio analítico sobre o processo de militarização das escolas públicas brasileiras, sob o enfoque dos direitos constitucional, administrativo e educacional. Parte da identificação e análise de fontes documentais nacionais e estaduais que estão na base da institucionalização dos modelos de militarização e explora, com base na Constituição e na legislação de direito público, alguns dos seus pontos jurídicos críticos. Pretende-se assim oferecer um enfoque original e contribuir com o debate sobre os inúmeros problemas jurídicos e de política educacional em discussão.
\end{abstract}

Palavras-chave: direito à educação; militarização; ensino militar; Programa Nacional das Escolas Cívico-Militares - Pecim.

\begin{abstract}
The article presents an analytical essay on the militarization process of Brazilian public schools, focusing on constitutional, administrative and educational rights. It begins by identifying and analyzing national and state documentary sources that underlie the institutionalization of militarization models. It also explores, based on the Constitution and public law, some of its critical legal points. It intends to provide an original approach and contribute to the debate on the numerous legal and educational policy issues under discussion.
\end{abstract}

Keywords: the right to education; militarization; basic education; National Program of the Civic-Military Schools - Pecim.

Resumen: El artículo presenta un ensayo analítico sobre el proceso de militarización de las escuelas públicas brasileñas, bajo el enfoque de los derechos constitucionales, administrativos y educativos. Parte de la identificación y análisis de fuentes documentales nacionales y estatales que se encuentran en la base de la institucionalización de los modelos de militarización y explora, con base en 
la Constitución y en la legislación del derecho público, algunos de sus puntos jurídicos críticos,. Se pretende, así, ofrecer un enfoque original y contribuir al debate sobre los diversos problemas jurídicos y de la política educativas en discusión.

Palabras clave: derecho a la educación; militarización; enseñanza militar; Programa Nacional de las Escuelas Cívico Militares - Pecim.

\section{INTRODUÇÃO}

Amplia-se no cenário educacional brasileiro da última década a presença, sobretudo nas redes estaduais, de escolas militares ou militarizadas, ou, conforme denominado no programa federal, "escolas cívico-militares" (BRASIL, 2019a). Embora a escola com viés militarizado ou diretamente geridas por militares não seja uma novidade há bastante tempo em diversos países, como Índia, Turquia e EUA (BENEVIDES; SOARES, 2019, p. 8), a diferença de denominação, no contexto atual brasileiro, expressa um modelo jurídico-administrativo em formulação, experimentação e implementação, que pode resultar, ao final, na consolidação de uma nova modalidade de ensino, com diretrizes e normas próprias.

Atualmente, são 17 (dezessete) os Colégios Militares do Exército e das Políticas Militares e Corpos de Bombeiros Militares (BRASIL; 2019b, p. 5). Regidos pela Lei $n^{\circ}$ 9.786/1999 (BRASIL, 1999) e regulamentos próprios (BRASIL, 2008), aos colégios militares cabe oferecer "de forma adicional às modalidades militares propriamente ditas, o ensino preparatório e assistencial de nível fundamental e médio (...) na forma da legislação federal pertinente, ressalvadas suas peculiaridades." (art. $7^{\circ}$ ). Entre as particularidades do modelo, além do objetivo de formação inicial de quadros militares, está o "regime disciplinar de natureza educativa" (art. $7^{\circ}, \$ 2^{\circ}$ ).

Os estados, por sua vez, no exercício de sua competência legislativa concorrente (Constituição Federal, art. 24, IX), regulamentaram o ensino militar no âmbito das forças auxiliares de segurança pública - Polícias Militares e Corpo de Bombeiros Militares. É nesse âmbito que foram criados os primeiros colégios militares estaduais, vinculados a tais instituições, antes de iniciado o ciclo de expansão contemporâneo cuja característica marcante é o processo de militarização de escolas comuns (civis) preexistentes, ou seja, a incorporação de agentes e regulamentos militares em escolas públicas, sob diferentes critérios e arranjos de gestão.

Em 2019 são 203 (duzentas e três) as escolas públicas estaduais e municipais militares e militarizadas, com perspectivas de expansão. Elas fazem parte da rede pública de ensino e são administradas por uma força militar específica, 
como a Polícia Militar ou o Corpo de Bombeiros Militares, e não contam com a participação do Ministério da Educação em sua criação. Destaca-se a mais antiga em funcionamento, a Escola Estadual Brigadeiro João Camarão Telles Ribeiro em Manaus/AM, ligada à Polícia Militar, que iniciou suas atividades em 1994. Entre as mais recentes a se tornar Cívico-Militar está o CED 03, de Sobradinho/DF, ligado à Polícia Militar do Distrito Federal. Suas atividades no modelo CívicoMilitar iniciaram concomitantemente ao ano letivo de 2019 da rede estadual de ensino do Distrito Federal. (BRASIL, 2019b, pp. 7-8). Ao longo desses 25 anos, cada localidade estabeleceu o arranjo administrativo que melhor se adaptou às suas necessidades e especificidades. Todas elas, porém, fundamentadas em valores como "patriotismo, civismo, respeito aos símbolos nacionais, noções de hierarquia e de disciplina, valorização da meritocracia e outros" (BRASIL, 2019b, p. 9).

Na reorganização do Ministério da Educação (MEC), no início de 2019, sob a presidência de Jair Bolsonaro, é incorporada à Secretaria de Educação Básica a atribuição de "promover, fomentar, acompanhar e avaliar, por meio de parcerias, a adoção por adesão do modelo de escolas cívico-militares nos sistemas de ensino municipais, estaduais e distrital tendo como base a gestão administrativa, educacional e didático-pedagógica adotada por colégios militares do Exército, Polícias e Bombeiros Militares" (Decreto 9.665/2019, art. 11, art. XVI - BRASIL, 2019).

Para isso é criada, no mesmo ato, a Subsecretaria de Fomento às Escolas Cívico-Militares $^{1}$ (Figura 1) responsável por desenvolver o Programa Nacional de Implantação das Escolas Cívico-Militares, anunciado posteriormente como parte do Compromisso Nacional da Educação Básica (BRASIL; MEC; CONSED; UNDIME, 2019), cujo objetivo quantitativo é "aplicar (sic!) 27 escolas por ano até o final de 2023, totalizando 108 Escolas Cívico-Militares em todos os Estados e Distrito Federal" (BRASIL, 2019b, p. 10). Tais escolas seriam resultado de parcerias entre a União e os entes federativos interessados em implantar o modelo, que, segundo a proposta, contará com recursos orçamentários próprios do governo federal, embora estes ainda não tenham sido previstos na PLOA 2020 já apresentada ao Congresso Nacional.

1 As atribuições detalhadas da Subsecretaria de Fomento às Escolas Cívico-Militares estão descritas no artigo 16 do Decreto $9.665 / 2019$. 

Militares

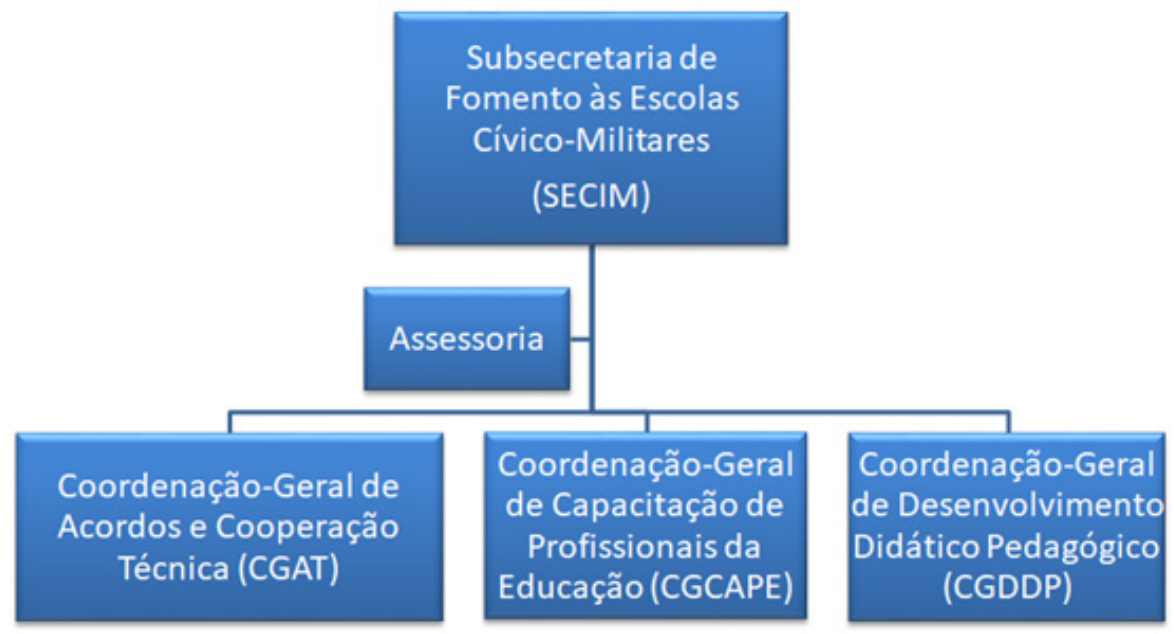

Fonte: Ministério da Educação, 2019

Partindo da premissa de que os colégios militares são mais eficientes e possuem melhores indicadores de qualidade (especialmente o IDEB), e considerando a necessidade de uniformização dos modelos existentes, o MEC estuda a normatização do modelo e a certificação das escolas que o aplicarem na sua integridade. $\mathrm{O}$ detalhamento dos requisitos para essa certificação ainda não foi apresentado, porém já se sabe que a participação militar estará pautada na presença dos militares na escola, atuando na função de tutoria (junto aos profissionais) e monitoria (junto aos alunos), com o objetivo de fortalecimento da gestão das escolas. A presença do militar, de acordo com o MEC, não significa a substituição do corpo docente, nem dos demais profissionais da educação. Ela viria para complementar e auxiliar em atribuições específicas relacionadas aos aspectos disciplinar e atitudinal do aluno fora da sala de aula, mas dentro do ambiente escolar. (BRASIL, 2019b. pp. 9-10). A figura 2 ilustra o modelo como a intersecção entre colégios militares e as escolas públicas no que diz respeito à gestão educacional, conforme apresentado pelo governo, aos padrões de ensino e aos modelos pedagógicos. 


\section{Figura 2 - Modelo das escolas cívico-militares}

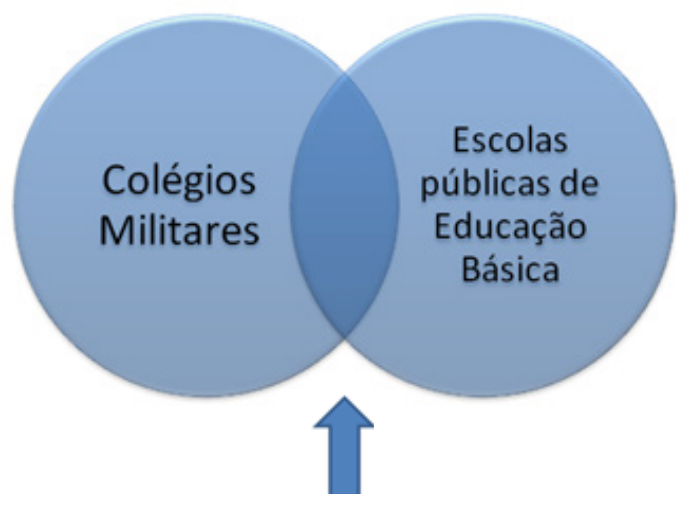

\section{Escolas cívico-militares: Gestão educacional, padrões de ensino e modelos pedagógicos}

Fonte: apresentação SECIM/SEB/MEC de 9 de maio de $2019^{2}$

A proposta do governo federal se inspira nos vários desenhos existentes nos estados, especialmente das regiões Centro-Oeste e Norte do país. Com uma das experiências mais antigas de militarização das escolas da rede pública, o estado de Goiás possui hoje uma lista de 60 escolas que já tiverem a militarização autorizada por meio de lei $^{3}$, na maioria delas a administração já é feita pela Polícia Militar.

Em complemento às críticas já produzidas pela literatura que vem analisando este modelo (GUIMARÃES; LAMOS, 2018; TAVARES, 2016), opostas aos falhos pressupostos técnicos e político-pedagógicos das políticas públicas de militarização escolar, este ensaio objetiva oferecer um quadro de análise dos aspectos especificamente jurídicos, tendo como base a definição da educação escolar como um direito humano fundamental na Constituição Federal, nos tratados internacionais, na legislação educacional e demais normas de direito público voltadas a viabilizar o exercício desse direito. Privilegiamos a análise sob três enfoques jurídicos: constitucional, educacional e administrativo.

2 Disponível em https://www2.camara.leg.br/atividade-legislativa/comissoes/comissoespermanentes/ce/seminarios-1/seminario-em-09-de-maio-de-2019-sobre-escolas-civico-militares Acesso em 29 ago. 2019.

3 Nas leis de aprovação, os colégios passam a ser denominados de Colégios Estaduais da Política Militar de Goiás - CEPMGs, confome LEI No 19.779, DE 18 DE JULHO DE 2017, do estado de Goiás. Disponível em http://www.gabinetecivil.go.gov.br/pagina_leis.php?id=21657. Acesso em 26 ago. 2019. Ver relação de escolas em https://www.portalcepmg.com.br/nossas-unidades/. Acesso em 26 ago. 2019. 
No próximo tópico, denominado "A militarização de escolas públicas sob o enfoque dos direitos constitucional e educacional", tomamos como base os princípios, direitos e garantias fundamentais da Constituição de 1988, o papel nela destinado às forças armadas e os objetivos e princípios do ensino, com o objetivo de explorar a incompatibilidade entre a militarização e o desenho normativo afirmado na Constituição, bem como a definição de educação como um direito humano e, mais especificamente, as implicações necessárias dessa definição nas diretrizes e objetivos educacionais. No tópico seguinte, adotamos o enfoque típico do direito administrativo, com o intuito de explorar os novos arranjos que vêm sendo implantados como forma de viabilizar as escolas militarizadas. Nesse tópico, cabe verificar desde as reformas administrativas nas secretarias e instituições de segurança pública até a ocupação dos cargos e funções públicas nas escolas e na gestão educacional.

Nosso objetivo de fundo é oferecer o quadro de análise jurídica aos projetos e iniciativas de militarização e não analisar todos os desenhos jurídicos e institucionais atualmente praticados nos estados e municípios. Diante disso, adotaremos como referência para a análise o programa e a legislação federal juntamente com a experiência de Goiás, uma vez que é nesse estado onde há uma trajetória mais consistente de militarização escolar, com fortes críticas por parte das organizações do campo educacional, farta produção legislativa e algum debate nos órgãos de controle jurisdicional. Além da legislação, a análise se faz com base em documentos oficiais, públicos ou solicitados via Lei de Acesso à Informação (Lei 12.527/2011), nas notícias veiculadas e na revisão da bibliografia sobre o tema.

\section{A MILITARIZAÇÃO DE ESCOLAS PÚBLICAS SOB O ENFOQUE DOS DIREITOS CONSTITUCIONAL E EDUCACIONAL}

O modelo constitucional brasileiro indica a adoção de um Estado alicerçado em bases de um pluralismo político. Fruto de uma convergência ideológica advinda da reconstrução democrática, não há como definir a identidade do texto constitucional a partir de um único viés da ideologia jurídica, seja ele liberal ou intervencionista. Existe de fato uma proposta programática e dirigente, porém, destacamos o caráter compromissário de todo o processo constituinte que culmina no texto aprovado 
O pluralismo da Constituição advém basicamente do seu caráter marcadamente compromissário, já que o Constituinte, na redação final do texto, optou por acolher e conciliar posições e reivindicações nem sempre afinadas entre si, resultantes das fortes pressões políticas exercidas pelas diversas tendências envolvidas no processo Constituinte. (SARLET, 2009, P.138)

Advinda de um período anterior autoritário, o texto constitucional é marcado por uma característica analítica, regulamentador, mesmo diante de uma concepção plural de ideias, notoriamente eclética, mantendo seu caráter dirigente.

A interpretação da Constituição afeta diretamente como definirmos a aplicação dos princípios constitucionais da educação, definidos no art. 206. De antemão já apontamos que as normas constitucionais podem ser definidoras de princípios ou regras, ambos com força normativa e, portanto, aplicabilidade imediata, porém com uma diferença jurídico-dogmática, polarizada na teoria constitucional nas concepções de Dworkin e Alexy. Os princípios cumprem importante papel quando definidos constitucionalmente e são adequados na perspectiva de um texto constitucional eclético com diversas expectativas normativas:

(...) os princípios constitucionais, enquanto normas do ponto de vista da estática jurídica, passam a ser um filtro fundamental em face da pluralidade de expectativas normativas existentes no ambiente do sistema jurídico, com pretensão de abrangência moral. (....) Uma constituição formada apenas de regras seria, perante um contexto social hipercomplexo, inadequada. Os princípios constitucionais, por implicarem certa distância do caso a decidir e uma relação mais flexível entre o antecedente e o consequente, são mais adequados a enfrentar a diversidade de expectativas normativas que circulam na sociedade. (NEVES, 2014, p. 233)

Compreendendo o papel dos princípios, o art. 206 da Constituição Federal destaca os princípios de cumprimento obrigatório para o ensino:

I - igualdade de condições para o acesso e permanência na escola; II - liberdade de aprender, ensinar, pesquisar e divulgar o pensamento, a arte e o saber; III - pluralismo de ideias e de concepções pedagógicas, e coexistência de instituições públicas e privadas de ensino; IV - gratuidade do ensino público em estabelecimentos oficiais; V - valorização dos profissionais da educação escolar, garantidos, na forma da lei, planos de carreira, com ingresso exclusivamente por concurso público de provas e títulos, aos das redes públicas; VI - gestão democrática do ensino público, na forma da lei; VII - garantia de padrão de qualidade. VIII - piso salarial profissional nacional para os profissionais da educação escolar pública, nos termos de lei federal. (BRASIL, 1988) 
Antes de detalhar os princípios, observamos que, pelas notícias veiculadas acerca da implantação das escolas cívico-militares, são estabelecidas diversas regras para os estudantes, tais como: proibição de gírias; proibição de paquera ou namoro (Contato físico "que denote envolvimento de cunho amoroso" é proibido); proibição de uso de batons ou esmaltes de unha; obrigação de bater continência e caminhar marchando; proibição de mascar chicletes; obrigação de corte de cabelo padronizado; proibição de qualquer crítica, considerando falta disciplinar grave "denegrir o nome da polícia ou de qualquer de seus membros. ${ }^{4}$

A proposta de uma padronização do comportamento discente, aliado a uma postura que fortalece a ausência de debate crítico e democrático não é admitido pelo nosso ordenamento jurídico.

Primeiramente, a escola deve cumprir o Princípio da Gestão Democrática, resultando em um ambiente que preza a participação nas definições do Projeto Político Pedagógico, tal participação alcança trabalhadores, gestores, estudantes e familiares. Portanto, as definições do que é admitida ou não na prática escolar deve ser definido de forma plural, e pela própria comunidade escolar. Nesse âmbito, encontra-se o direito à organização autônoma dos estudantes em entidades próprias, cuja atuação não pode ser limitada ou tutelada (AUTOR; AUTOR).

O Supremo Tribunal Federal, por sua vez, na ADI 2.997, apesar de considerar inconstitucional o estabelecimento de eleições diretas para diretor de escola (com definição de mandato) assegurou que o princípio da gestão democrática deve ser obrigatoriamente cumprido pelos entes de direito público. Segundo voto do Ministro Cezar Peluso, ao comentar o art. 206, VI da Constituição Federal (princípio da gestão democrática) informa que o dispositivo constitucional permite ao legislador ordinário experimentar formas de participação da comunidade escolar na escolha dos dirigentes escolares. Com tal entendimento, mesmo no modelo cívico-militar deve ser garantido à escolha de dirigentes de forma democrática, o que não ocorre. (STF, 2009, online)

De igual modo, os princípios da liberdade de aprender, ensinar, pesquisar e divulgar o pensamento, a arte e o saber e do pluralismo de ideias e de concepções pedagógicas, e coexistência de instituições públicas e privadas de ensino podem sofrer sério risco, já que o ambiente voltado ao controle demonstra não ser o mais propício para o desenvolvimento de uma prática educacional com pluralismo de ideias É fácil imaginar situações em que os conflitos oriundos da cultura e práticas dos adolescentes e da obediência a um determinado código militar irão gerar.

4 Disponível em: http://g1.globo.com/jornal-da-globo/noticia/2014/01/policia-militar-vaiadministrar-dez-escolas-publicas-do-estado-de-goias.html, acesso em: 23.08.2019 
A cobrança de taxas nas escolas militarizadas, noticiadas em Goiás no valor de $\mathrm{R} \$ 70,00$ (setenta reais) além de despesas com fardamento ofende, frontalmente, o princípio da gratuidade do ensino, já definido de que o acesso à educação, até para adequação ao inciso I do art. 206 (igualdade de condições para o acesso e permanência na escola) deve ser garantido de forma não onerosa. Nesse sentido são as diversas decisões judiciais de efetivação de transporte escolar, proibição de cobranças de taxas e fardamentos. O Supremo Tribunal Federal tem verbete vinculante sobre o tema, de $n^{\circ} 12$, com a seguinte redação: "A cobrança de taxa de matrícula nas universidades públicas viola o disposto no art. 206, IV, da Constituição Federal.” (STF, 2008, online)

No julgamento do RE 562.779 que julgou tema afeto a gratuidade do ensino público, em especial quanto à taxa em universidades, restou assentado no acórdão que o princípio da gratuidade deve ser interpretado sistematicamente com o caráter universal dos direitos humanos, dialogando com o princípio da igualdade de acesso. $\mathrm{O}$ direito à educação é erguido a verdadeiro serviço público essencial, que deve ser estendido a todos. Segundo o Supremo:

Não colhe, pois, o argumento da recorrente, calcado numa exegese restritiva do art. 208 da Lei Maior, segundo o qual a obrigação do Estado no concernente à gratuidade da educação estaria restrita ao ensino fundamental obrigatório, e que, com relação ao ensino médio, ela quedaria circunscrita à garantia de sua progressiva universalização. E ainda: que o dever do Estado, quanto aos níveis mais elevados de ensino, limitar-se-ia a assegurar o acesso aos mesmos segundo a capacidade de cada um (STJ, 2008, online). Importante destacar: a gratuidade é devida em todas as etapas da educação, inclusive no ensino superior. Em 2017 o Supremo Tribunal Federal mitigou a tese, considerando que cursos de especialização podem cobrar mensalidades, mesmo em Universidades públicas.

O termo utilizado pela Constituição é que essas são as tarefas de "manutenção e desenvolvimento do ensino". Consequentemente, são a elas que se estende o princípio da gratuidade. Nada obstante, é possível às universidades, no âmbito de sua autonomia didático-científica, regulamentar, em harmonia com a legislação, as atividades destinadas preponderantemente à extensão universitária, sendo-lhes, nessa condição, possível a instituição de tarifa. Noutras palavras, a garantia constitucional da gratuidade de ensino não obsta a cobrança, por universidades públicas, de mensalidade em curso de especialização (STJ, 2017, online).

No julgamento, foi diferenciado atividade de manutenção e desenvolvimento do ensino de atividades de extensão, possibilitando às últimas, através da autonomia universitária a instituição de taxa. 
No caso do modelo cívico-militar existe uma incompatibilidade da cobrança de qualquer tipo de taxa e os princípios constitucionais da gratuidade e da igualdade de acesso. Mesmo sob o manto de "contribuição voluntária" e de que o uso do recurso é realizado na própria escola, a cobrança, além de atingir as famílias de baixa renda, proporciona desigual acesso, constituindo verdadeiro retrocesso na prestação do serviço público educacional.

O princípio da qualidade da educação também é violado. Não podemos admitir qualidade sem democracia. A qualidade deve ser construída democraticamente. Existe concretamente uma disputa de concepções pedagógicas que influem na concepção de qualidade da educação. Para além dos insumos indispensáveis à prática pedagógica, a dimensão da qualidade dialoga com a pluralidade de ideias, pensamento, arte e saber. É inconcebível uma educação de qualidade em um ambiente que não existe liberdade de expressão e de práticas pedagógicas.

Por fim, o princípio da valorização dos profissionais é ameaçado, já que os profissionais da educação ficam vinculados ao regime militar estabelecido, atingindo de forma central a liberdade de associação e expressão desses professores.

\section{A MILITARIZAÇÃO DAS ESCOLAS PÚBLICAS SOB O ENFOQUE DO DIREITO ADMINISTRATIVO}

O direito administrativo é o ramo do direito público que disciplina o exercício da função administrativa, bem como pessoas e órgãos que a desempenham (MELLO, 2016, p. 29). Analisar o processo de militarização das escolas sob o enfoque do direito administrativo significa olhar para os aspectos do regime jurídico da operacionalização desse modelo: os princípios que orientam a ação estatal no sentido do interesse público; as figuras da administração pública utilizadas e sua organização interna; as formas de contratação e eventuais parcerias com entidades privadas; os agentes públicos; os bens públicos; os procedimentos administrativos de tomada de decisão; a transparência dos atos; e as formas de controle sobre a administração pública.

Como o modelo no âmbito federal ainda está em formulação, a análise sobre a militarização das escolas se dá com base nos documentos já apresentados pelo MEC e a partir da leitura de documentos sobre as experiências em andamento no âmbito dos estados, especialmente o caso do estado de Goiás.

A primeira questão que se coloca é se a proposta de transformação de escolas públicas em escolas cívico-militares, sem alteração da CF e de legislação federal e sem base na representação política e na regra da maioria, atende ao 
interesse público. Num Estado Democrático de Direito, para que não haja subjetividade na definição do que é interesse público, este deve ser definido na lei. Nesse sentido, o modelo de militarização proposto fere o princípio da legalidade (art. 37, CF) e da finalidade pública (art. $2^{\circ}$ da Lei 9.784/1999, BRASIL, 1999), pois na atuação do Estado, "não há liberdade nem vontade pessoal. Enquanto na administração particular é lícito fazer tudo que a lei não proíbe, na Administração Pública só é permitido fazer o que a lei autoriza” (MEIRELLES, 2012, p. 89).

A transformação das escolas civis em cívico-militares tem sido justificada como medida para: i) atenuar altos índices de violência em áreas de periferia; ii) melhorar o Índice de Desenvolvimento da Educação Básica (Ideb) das escolas. A primeira justificativa parecer atribuir à escola pública uma nova missão, diferente daquela que a legislação educacional prescreve, o que configuraria desvio de finalidade. A segunda poderia ser uma justificativa plausível, apoiando-se no princípio da eficiência da administração pública, mas isso não se confirma, como argumentamos adiante.

De acordo com o princípio da finalidade pública, a administração deve sempre atuar para alcançar o fim público definido pela lei. Sem finalidade definida em lei, todo ato que tiver fim diverso daquele explícita ou implicitamente previsto na regra de competência, poderá ser invalidado por desvio de finalidade. (Lei 4717/1968, art.2, parágrafo único, “e”, BRASIL, 1968).

Uma recente alteração da CF, por meio da EC 101/2019 (inclusão do S $3^{\circ}$ do art. 42), passou a permitir que militares dos Estados, do Distrito Federal e dos Territórios possam acumular seus cargos de militares dos Estados com: i) um cargo de professor; ii) um cargo técnico ou científico; ou iii) um cargo ou emprego privativo de profissionais de saúde, com profissões regulamentadas (art. 37, inciso XVI), com prevalência da atividade militar. $\mathrm{Na}$ justificação desta alteração, à época de sua proposição, já aparecia o objetivo de aumentar "a interação construtiva entre os operadores da segurança pública e estudantes desde as primeiras séries do ensino fundamental", no sentido de "operar uma importante união entre o conhecimento e a inexperiência nessa importante prioridade para população que é o combate a violência e a criminalidade, onde o beneficiado será a sociedade (sic)." Além da motivação ser questionável, é importante entender como se dá o acúmulo de funções de policiamento e ensino entre os militares e se há respaldo legal para o exercício de uma terceira função - a de administração das escolas da rede pública estadual.

Do ponto de vista do arranjo institucional relacionado às funções do Estado, conforme o art. 144 da Constituição Federal (BRASIL, 1988): 
$\int 5^{\circ}$ Às polícias militares cabem a polícia ostensiva e a preservação da ordem pública; aos corpos de bombeiros militares, além das atribuições definidas em lei, incumbe a execução de atividades de defesa civil.

Como se percebe da leitura do dispositivo, não está dentre as atribuições da política e dos bombeiros militares administrar as escolas públicas. Existe aqui um nítido desvio de função nas atividades desenvolvidas. Tal desvio pode configurar, inclusive, crime de improbidade administrativa do gestor que autorizar tal medida, conforme Lei no 8429/1992 (BRASIL, 1992).

A segurança pública destina-se à preservação da ordem pública e da incolumidade das pessoas e do patrimônio, segundo caput do art. 144 da Constituição Federal (BRASIL, 1988). Não há qualquer menção, na função constitucionalmente reservada às forças de segurança, relacionada à administração de escolas. $\mathrm{O}$ arranjo realizado denota uma compreensão equivocada do papel reservado às polícias em relação à educação. Ocorre claro desvio de função, com flagrante inconstitucionalidade diante da incompatibilidade das atribuições do órgão de segurança pública e sua relação com o direito à educação.

Sem respaldo legal, com desvio de finalidade e desvio de função, como uma proposta pode ser considerada eficiente? Pelo princípio da eficiência, o Estado deve atuar de modo mais oportuno e adequado aos resultados que pretende alcançar, utilizando meios idôneos e menos onerosos para a administração. Como visto, o modelo cívico-militar, embora propagado como solução para um apressado diagnóstico de ineficiência das escolas da rede pública, não pode ser exemplo de aplicação do princípio da eficiência.

A competência para a criação do referido programa também pode ser questionada sob dois aspectos. O primeiro deles diz respeito aos limites da atuação da União para tratar da organização dos sistemas estaduais e municipais de ensino, considerando o desenho federativo e a autonomia dos entes previstos na Constituição Federal. Argumenta-se que tanto a criação do programa quanto da Subsecretaria de Fomento às Escolas Cívico-Militares, vinculada à Secretaria de Educação Básica do MEC (Decreto 9.665/2019) - a pretexto de promover mera reorganização administrativa do MEC, não encontram respaldo na divisão constitucional de competências. Em relação ao segundo aspecto, o programa federal cria atribuições para as Polícias Militares e Bombeiros que não estão previstas na Constituição Federal, como visto acima. As Polícias Militares e Bombeiros estão na esfera da autonomia estadual e subordinam-se aos governadores dos estados e do Distrito Federal (art. 42 e art. $144, \$ 6,^{\circ}$ da CF, Brasil, 1988). Por essas razões, ainda que se considere que o papel da União no programa é meramente supletivo 
em relação à educação, a ingerência da União na organização das instituições responsáveis pela segurança pública parece ferir diretamente a autonomia dos estados.

Mesmo no caso das experiências estaduais recentes de inserção das instituições de segurança pública, em especial as polícias militares, na gestão das unidades públicas de ensino nos sistemas estaduais de educação, várias ilegalidades vêm sendo apontadas nas medidas de operacionalização dessas escolas, como em Goiás (TAVARES, 2016). Nesse estado, ainda que haja a aprovação de uma lei, que autoriza o processo de militarização de cada escola, esta é apresentada sem motivação técnica e jurídica suficiente, não suprindo o desvio de finalidade da proposta, já argumentado.

Após a aprovação da lei, a operacionalização da mudança de gestão das escolas se dá por meio de um Termo de Cooperação Técnico-Pedagógico entre a Secretaria de Educação, Cultura e Esporte e a Secretaria de Estado da Segurança Pública, por meio da Polícia Militar. Pelas cláusulas do termo, faz-se a cessão do uso do imóvel da escola para a administração militar e a pasta da educação se compromete a ceder 100\% (cem por cento) dos recursos humanos (professores e pessoal administrativo) necessários ao desenvolvimento das atividades. O termo também trata da cobrança da contribuição comunitária "voluntária", além de outros pontos relacionados a questões pedagógicas. O detalhamento das regras de funcionamento dessas escolas militarizadas, está no Regimento Interno dos Colégios Estaduais da Política Militar (GOIÁS, 2018), que já passou por diversas atualizações do seu texto, ao que parece para tentar superar as inconstitucionalidades e ilegalidades do novo modelo. Uma das alterações é exatamente a que dispunha sobre a administração dos recursos de contribuição voluntária, antes atribuída ao $\mathrm{CEPMG}^{5}$ e atualmente tratada como verba sob a decisão da $\mathrm{APM}^{6}$.

A cobrança de taxas, do ponto de vista administrativo, deveria ter previsão legal e seguir todas as regras da contabilidade pública, integrando com transparência as receitas públicas. Para Tavares,

5 Conforme Guimarães e Lamos (2018, P. 77), a redação do art. 147 do Regimento Interno assim dispunha: "Art. 147. São contribuições voluntárias doadas pelos pais ou responsáveis pelos alunos. $\$ 1^{\circ}$ Contribuição esporádica, mediante solicitação e destinação prévia, com material de uso geral ou pedagógico destina a prover a seção de Recursos Didáticos e Serviços Gerais. $\$ 2^{\circ}$ Contribuição voluntária feita por cada pai ou responsável pelos alunos, durante o ano letivo, destinada a prover despesas gerais do CPMG para a melhoria do ensino." (GOIÁS, 2015)

6 Atualmente, o art. 147 trata de outro assunto e a disciplina das contribuições é feita pela combinação do art. $10, \$ 2^{\circ}$, I com o art. 79 do Regimento Interno (GOIÁS, 2018), atribuindo à Associação de Pais, Mestres e Funcionários (APMF) maior responsabilidade. 
o Militar que aceita receber valores informais de particulares, sem que esse dinheiro integre a contabilidade pública, está a contribuir para o vilipêndio do princípio da gratuidade do ensino público e, destarte, como falta grave. Ademais, deve-se indagar sobre como se dá a escrituração e a fiscalização, por órgãos como o TCE e o MP, do dinheiro que segue para um serviço estatal, como escolas (2016, p. 57).

Em relação à estrutura administrativa das duas áreas do governo de Goiás - Secretaria de Educação e Polícia Militar - chama a atenção o fato de que as escolas militarizadas passam a integrar o organograma do Comando de Ensino da Polícia Militar de Goiás, conforme figura 3. Os colégios estaduais militares ficam ligados a esse Comando, com uma estrutura (figura 4) cujos postos de direção da escola - Comandante Diretor e Subcomandante (Vice Direção) serão ocupados por militares e não por profissionais do magistério, como é a diretriz da Lei de Diretrizes e Bases da Educação - LDB (BRASIL, 1996). De acordo com a Lei n. 14.044, de 2001 (GOIÁS, 2001), que dispõe sobre os Colégios Estaduais da Polícia Militar do Estado de Goiás estes ficam sob comando e direção de oficiais da ativa (QOPM) dos postos de Tenente Coronel e Major, com graduação acadêmica superior e possuidores de curso de especialização em ensino ou equivalente, obedecida a estrutura orgânica prevista pela Secretaria da Educação. Os comandantes-diretores das unidades são designados pelo Comandante-Geral da Polícia Militar. A secretaria-geral de cada escola fica diretamente ligada à Diretoria de Ensino, Instrução e Pesquisa da Polícia Militar.

Figura 3 - Estrutura Comando de Ensino da Polícia Militar de Goiás

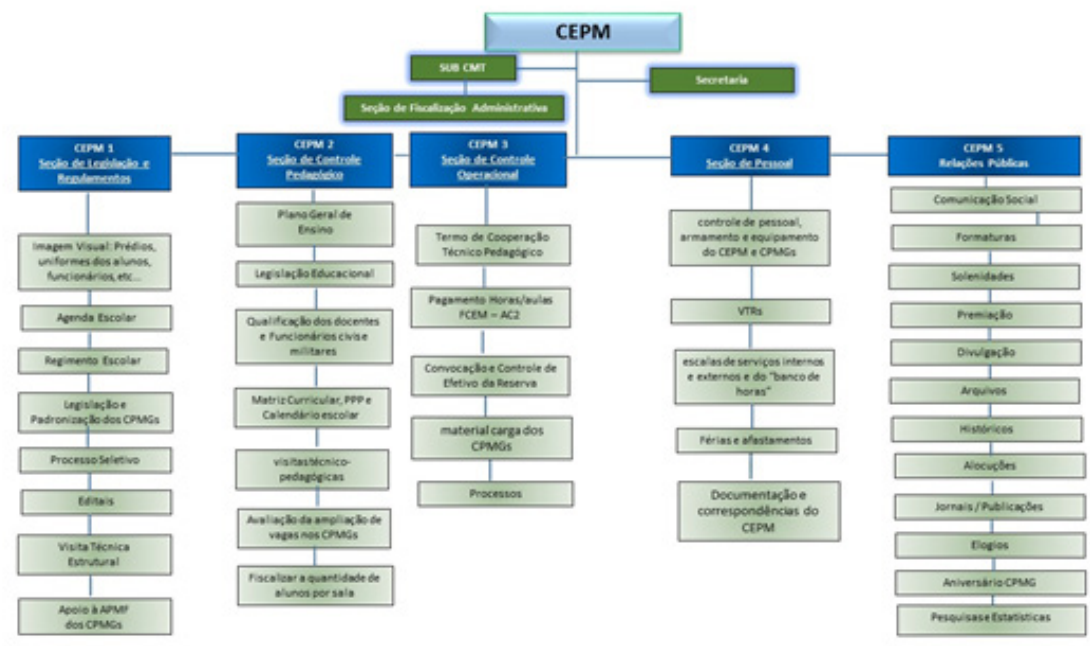

Fonte: Portal CPEMG, GOIÁs, 2019 


\section{Figura 4 - Estrutura organizacional dos colégios militares de Goiás}

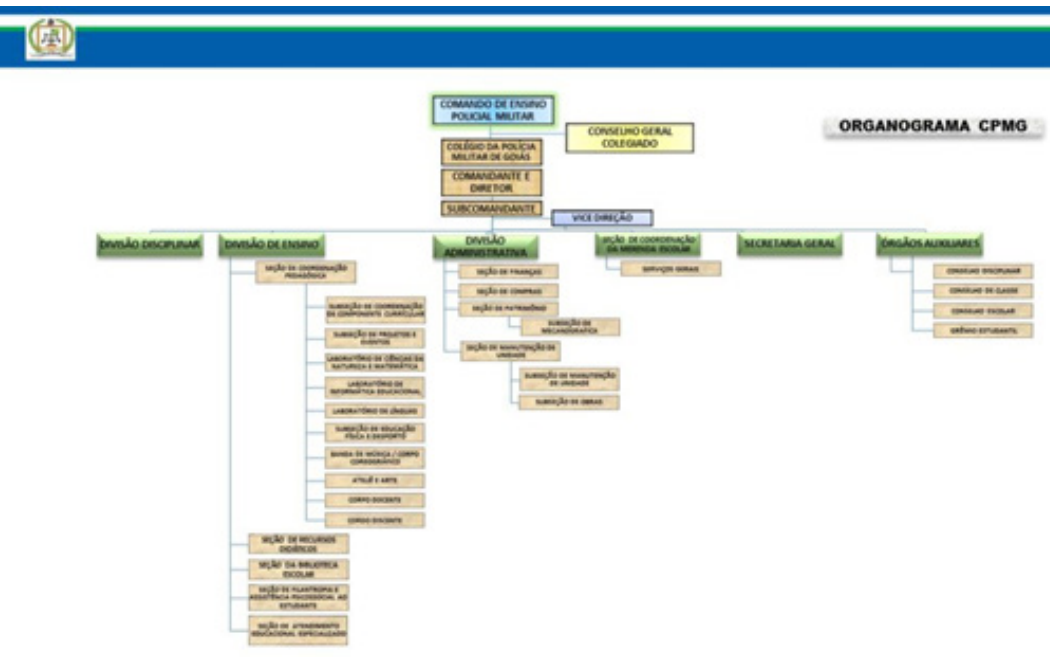

Fonte: Portal CPEMG, GOIÁS, 2019

No âmbito da Secretaria de Educação, vinculada à Subsecretaria de Execução da Política Educacional, há uma Superintendência de Segurança Escolar e Colégio Militar, que conta com duas gerências, criada pela Lei no 19.865/2017 (GOIÁS, 2017). Pelo parágrafo único do art. $1^{\circ}$ da referida lei, as funções inerentes aos cargos em comissão de Superintendente de Segurança Escolar e Colégio Militar, Gerente de Segurança Escolar e Gerente de Colégio Militar, são consideradas de natureza policial-militar. Espantosamente, a lei não disciplina as competências das áreas que cria.

Em relação aos cargos, cada vez que se aprova a militarização de uma escola, em Goiás, extinguem-se os cargos de diretoria e secretaria vinculados à Secretaria de Educação e criam-se funções comissionadas de administração da educação militar no âmbito da Política Militar.

Esse desenho organizacional, além do desvio de função dos militares que passam a assumir tarefas diferentes daquelas que Constituição Federal previu, como já argumentamos, não deixa claro como se coordenam as duas carreiras de professor (civil e militar) na escola, nem como se dá a relação entre escolas civis e militarizadas na rede. Além dos prejuízos que isso pode ocasionar para a boa prestação do serviço educacional, é possível que haja questionamentos (inclusive judiciais) no sentido de equiparação de cargos, carreiras e salários, gerando insegurança jurídica na gestão das escolas. 
Diante das inconsistências e irregularidades do modelo das escolas cívico-militares, restam outras questões a aprofundar: i) como será regulamentado o acesso a essas escolas? A existência de vagas reservadas para familiares de militares ou provas de acesso em algumas experiências pode conviver com a universalidade do direito à educação, inclusive em relação ao direito de estudar perto de casa? ii) como serão cumpridas as exigências de transparência ativa e passiva previstas na Lei de Acesso à Informação (BRASIL, 2011)? Questões de segurança podem ser sobrepor à cultura da transparência?; iii) como e em relação a quais órgãos e agentes vão se dar os controles internos e externos? iv) como será feito o cômputo das despesas obrigatórias em educação (natureza das despesas, pagamento e capacitação de policiais militares e bombeiros, tipos de despesa no orçamento da Política Militar)?

\section{CONSIDERAÇÕES FINAIS}

A crescente militarização das escolas públicas é, portanto, inconstitucional por diversas perspectivas, além disso, viola os tratados internacionais assinados pelo Brasil. Na perspectiva do direito à educação, viola frontalmente os princípios da "liberdade de aprender, ensinar, pesquisar e divulgar o pensamento, a arte e o saber", do "pluralismo de ideias e de concepções pedagógicas" e da gestão democrática do ensino público, na forma da lei (incisos II, III e VI do art. 206, respectivamente). Por esses princípios, devem ser assegurados amplos canais que viabilizem a discussão aberta e democrática sobre todos os temas do processo educativo com a participação dos trabalhadores profissionais da educação (direções escolares, supervisões, coordenações pedagógicas, docentes professores, agentes escolares, e gestores), estudantes, familiares dos alunos e da comunidade local. Além disso, tal medida é um retrocesso inconstitucional na implementação dos princípios da valorização do magistério e da garantia do padrão de qualidade do ensino. A LDB, ao regulamentar a prerrogativa de autonomia das escolas determina que esta deve ser progressivamente assegurada, em vertente oposta à intervenção de militares na gestão escolar (LDB, art. 15).

Essas garantias jurídico-constitucionais, por sua vez, dão base à construção das Diretrizes Curriculares Nacionais da Educação Básica, cujos objetivos e propósitos não comportam o princípio pedagógico das escolas militarizadas, comumente definido como "hierarquia e disciplina". No tocante aos profissionais do magistério, a militarização viola frontalmente o artigo 61 da LDB, que delimita quem está habilitado e legalmente autorizado ao trabalho no ensino, são eles os professores e os trabalhadores da educação com habilitação específica. Em função destas características, é evidente que a militarização escolar conflita abertamente 
com o modelo de educação estabelecido na Constituição de 1988, porque seus princípios de hierarquia e disciplina não podem ser compatibilizados com o caráter democrático processo educativo, único meio de garantir-se a próprio pluralismo e respeito aos processos de formação de crianças e adolescentes.

Há nesse ponto, sob o enfoque do direito administrativo, um patente desvio de função das instituições militares e, como consequência, dos servidores públicos militares, uma vez que nas iniciativas de militarização estes passam a exercer uma parcela significativa do trabalho atribuído aos cargos e funções do magistério.

Com isso, portanto, demonstramos que, por ora, o processo de militarização de escolas comuns e as mudanças legislativas e nas práticas políticopedagógicas daí decorrentes, vem apresentando um conjunto de incoerências e potenciais tensões e oposições quando confrontadas com a legislação educacional e o direito à educação em sentido amplo. Há pontos de resistência jurídica e judicial a serem explorados pelos defensores de escola plural e democrática. Por outro lado, é necessário dedicar atenção ao avanço das reformas normativas que objetivam dar uma legalidade formal às escolas militarizadas ou cívico-militares, o que pode redundar no surgimento de uma nova modalidade de ensino, de constitucionalidade e legalidade questionáveis. Lamentavelmente, uma modalidade compatível com os tempos de avanço autoritário que vivemos.

\section{REFERENNCIAS}

\section{BRASIL. Constituição da República Federativa do Brasil de 1988.} Disponível em http://www.planalto.gov.br/ccivil_03/constituicao/ constituicao.htm. Acesso em 19 ago. 2019.

BRASIL. Lei $\mathbf{n}^{\circ}$ 4.717, de 29 de junho de 1965. Regula a ação popular. Disponível em: http://www.planalto.gov.br/ccivil_03/leis/L4717.htm. Acesso em: 19 ago. 2019.

BRASIL. Lei $\mathbf{n}^{\mathbf{o}} \mathbf{8 4 2 9}$, de 2 de junho de 1992. Lei de improbidade administrativa. Disponível em: http://www.planalto.gov.br/ccivil_03/leis/ 18429.htm. Acesso em: 19 ago. 2019.

BRASIL. Lei ${ }^{\mathbf{0}}$ 9.394, de 20 de dezembro de 1996. Lei de Diretrizes e Bases da Educação. Disponível em: http://www.planalto.gov.br/ccivil_03/LEIS/L9394. htm. Acesso em: 12 ago. 2019. 
BRASIL. Lei $\mathbf{n}^{\mathbf{0}} \mathbf{9 . 7 8 6}$, de 8 de fevereiro de 1999. Dispõe sobre o ensino no Exército Brasileiro. Disponível em: http://www.planalto.gov.br/ccivil_03/leis/ L9786.htm. Acesso em: 19 ago. 2019.

BRASIL. Lei 9.784, de 29 de janeiro de 1999. Regula o processo administrativo no âmbito da Administração Pública Federal. Disponível em: http:// www.planalto. gov.br/ccivil_03/leis/19784.htm. Acesso em 10 ago. 2019.

BRASIL. Lei $\mathbf{n}^{\mathbf{0}}$ 12.527, de 18 de novembro de 2011. Lei de Acesso à Informação. Disponível em : http://www.planalto.gov.br/ccivil_03/ _ato2011-2014/2011/lei/112527.htm. Acesso em 2 ago. 2019.

BRASIL. Decreto $\mathbf{n}^{\mathbf{0}} \mathbf{9 . 6 6 5}$, de 2 de janeiro de 2019. Aprova a Estrutura Regimental e o Quadro Demonstrativo dos Cargos em Comissão e das Funções de Confiança do Ministério da Educação. Disponível em http://www.planalto. gov.br/ccivil_03/_ato2019-2022/2019/Decreto/D9665.htm . Acesso em 29 ago. 2019.

BRASIL. Comando do Exército. Portaria n ${ }^{\mathbf{0}} 042$ (R-69), de 6 de fevereiro de 2008. Disponível em: http://www.cmsm.eb.mil.br/phocadownload/legislacao/ regulamentos/03_Portaria_042_R69-2008.pdf Acesso em: 29 ago. 2019.

BRASIL; MEC. Dados - Pedido 23480015691201912. Acesso à Informação, 11/07/2019, 2019a. Disponível em: http://www.consultaesic.cgu.gov.br/busca/ dados/Lists/Pedido/Item/displayifs.aspx?List=0c839f31-47d7-4485-ab65-ab0c ee9cf8fe $\& I D=779626 \&$ Source $=$ http $\% 3 \mathrm{~A} \% 2 \mathrm{~F} \% 2 \mathrm{Fwww} \% 2 \mathrm{E}$ consultaesic $\% 2 \mathrm{E}$ cgu $\% 2$ Egov $\% 2 \mathrm{Ebr} \% 2 \mathrm{Fbusca} \% 2 \mathrm{FSitePages} \% 2$ Fresultadopesquisa $\% 2 \mathrm{Easpx} \%$ 3Fk\%3D23480015691201912\&Web=88cc5f44-8cfe-4964-8ff4-376b5ebb3bef. Acesso em: 22 ago. 2019.

BRASIL; MEC. Estudo para Criação das Escolas Cívico-Militares. Acesso à Informação, 11/07/2019, 2019. In: BRASIL; MEC. Dados - Pedido 23480015691201912. Acesso à Informação, 11/07/2019, 2019b. Disponível em: http://www.consultaesic.cgu.gov.br/busca/dados/Lists/Pedido/Item/ displayifs.aspx?List $=0 \mathrm{c} 839 \mathrm{f3} 1-47 \mathrm{~d} 7-4485-\mathrm{ab} 65-\mathrm{ab} 0 \mathrm{cee} 9 \mathrm{cf8fe} \& \mathrm{ID}=779626 \& \mathrm{Sou}$ rce $=$ http $\% 3 \mathrm{~A} \% 2 \mathrm{~F} \% 2 \mathrm{Fwww} \% 2 \mathrm{Econsultaesic} \% 2 \mathrm{Ecgu} \% 2 \mathrm{Egov} \% 2 \mathrm{Ebr} \% 2 \mathrm{Fbusc}$ a $\% 2$ FSitePages $\% 2$ Fresultadopesquisa $\% 2$ Easpx $\% 3 F k \% 3 D 23480015691201912$ $\& W e b=88 c c 5 f 44-8 c f e-4964-8 f f 4-376 b 5$ ebb3bef. Acesso em: 22 ago. 2019. 
BRASIL; MEC; CONSED; UNDIME. Compromisso Nacional pela Educação Básica. Brasília: MEC, 2019. Disponível em: http://portal.mec.gov.br/ images/11.07.2019_Apresentacao-ed-basica.pdf. Acesso em: 10 ago. 2019.

GOIÁS. Lei $\mathbf{n}^{\mathbf{0}} \mathbf{1 4 . 0 4 4}$, de 21 de dezembro de 2001. Dispõe sobre as unidades do Colégio da Polícia Militar do Estado de Goiás (CPMG). Disponível em: http://www.gabinetecivil.go.gov.br/pagina_leis.php?id=2151. Acesso em: 2 jul. 2019.

GOIÁS. Lei $\mathbf{n}^{\mathbf{0}} \mathbf{1 4 . 0 5 0}$, de 21 de dezembro de 2001. Dispõe sobre a criação, instalação e transferência de Unidades na Polícia Militar do Estado de Goiás. Disponível em: http://www.gabinetecivil.go.gov.br/pagina_leis.php?id=2157. Acesso em: 1 set. 2019.

GOIÁS. Lei $\mathbf{n}^{\mathbf{0}} \mathbf{1 6 . 1 5 2}$, de 26 de outubro de 2007. Promove a fusão das Unidades Escolares da Secretaria da Educação e da Polícia Militar que especifica. Disponível em: http://www.gabinetecivil.go.gov.br/pagina_leis.php? id $=7309$. Acesso em: 1 set. 2019.

GOIÁS. Lei $\mathbf{n}^{\mathbf{0}} \mathbf{1 4 . 0 4 4}$ de 25 de janeiro de 2011. Dispõe sobre a organização administrativa do Poder Executivo. Disponível em http://www.gabinetecivil. goias.gov.br/leis_ordinarias/2011/lei_17257.htm. Acesso em: 1 set. 2019.

GOIÁS. Lei $\mathbf{n}^{\mathbf{0}} \mathbf{1 8 . 5 5 6}$, de 25 de junho de 2014. Dispõe sobre a criação do Colégio da Polícia Militar de Goiás - CPMG - que menciona e dá outras providências. Disponível em: http://www.gabinetecivil.go.gov.br/ pagina_leis.php?id=11494. Acesso em: 1 set. 2019.

GOIÁS. Lei $\mathbf{n}^{\mathbf{0}} \mathbf{1 8 . 9 6 7}$, de 22 de julho de 2015. Dispõe sobre a transformação das unidades de ensino que especifica em Colégios Militares e dá outras providências. Disponível em: http://www.gabinetecivil.go.gov.br/ pagina_leis.php?id=14192. Acesso em: 1 set. 2019.

GOIÁS. Lei n. 19865 de 16 de outubro de 2017. Introduz alterações na organização administrativa do Poder Executivo. Disponível em http://www. gabinetecivil.goias.gov.br/leis_ordinarias/2011/lei_17257.htm. Acesso em: 1 set. 2019. 
GOIÁS. Polícia Militar do EStado de Goiás. Comando de Ensino Policial Militar. Regimento Interno dos Colégios Estaduais Militares de Goiás, 2018. Disponível em: https://www.portalcepmg.com.br/wp-content/ uploads/2018/05/document.pdf. Acesso em: 1 set. 2019

GOIÁS. Comando de Ensino Policial Militar. Portal CEPMG, 2019. Disponível em https://www.portalcepmg.com.br/estrutura-organizacional/. Acesso em: 1 set. 2019.

GUIMARES, Paula Cristina Pereira; LAMOS, Rodrigo de Azevedo Cruz. Militarização das escolas da rede estadual de Goiás: a nova onda conservadora. Revista Pedagógica, v. 20, n 43, jan./abr. 2018, pp. 66-80.

MEIRELLES, Hely Lopes. Direito Administrativo Brasileiro, $38^{a}$ ed. São Paulo: Malheiros, 2012.

MELLO, Celso Antônio Bandeira de. Curso de Direito Administrativo. 33a ed. São Paulo: Malheiros, 2016.

MENEZES, V. V.; SOARES, R. B. DIFERENCIAL DE DESEMPENHO DAS ESCOLAS MILITARES: BONS ALUNOS OU BOA ESCOLA? Encontros Universitários da UFC, v. 2, n. 1, p. 1104, 2019. Disponível em: https://www.bnb.gov.br/documents/160445/960917/DIFERENCIAL_DE_ DESEMPENHO_DAS_ESCOLAS_MILITARES.pdf/7ae9ef81-9687-46cbb501-766ccef1cba2. Acesso em 22 ago. 2019.

NEVES, Marcelo. Entre Hidra e Hércules: princípios e regras constitucionais como diferença paradoxal do sistema jurídico. 2. Ed. São Paulo: Editora WMF Martins Fontes, 2014.

SARLET, Ingo Wolgang. A eficácia dos direitos fundamentais: uma teoria geral dos direitos fundamentais na perspectiva constitucional. 10. Ed. Porto Alegre: Livraria do Advogado, 2009.

SUPREMO TRIBUNAL FEDERAL RECURSO EXTRAORDINÁRIO: 597.854 - GO; Relator: MIN. EDSON FACHIN; DJ Nr. 30 do dia 15/02/2017; disponível em: http://portal.stf.jus.br/processos/detalhe. asp? incidente $=2666225$; acesso em 01 set. 2019 . 
SUPREMO TRIBUNAL FEDERAL RECURSO EXTRAORDINÁRIO: 562.779 - MG; Relator: MIN. RICARDO LEWANDOWSKI; DJ Nr. 179 do dia 17/09/2007; disponível em: http://portal.stf.jus.br/processos/detalhe. asp? incidente $=2556752$; acesso em 01 set. 2019.

TAVARES, Francisco Mata Machado. Quem quer manter a ordem? A ilegalidade da militarização das escolas em Goiás. In: Estado de Exceção Escolar: uma avaliação crítica das escolas militarizadas / Ian Caetano de Oliveira, Victor Hugo Viegas de Freitas Silva, organizadores. Aparecida de Goiânia: Escultura produções editoriais, 2016.

VELOSO, Ellen Ribeiro; OLIVEIRA, Nathália Pereira. Nós perdemos a consciência? Apontamentos sobre a militarização de escolas públicas estaduais de ensino médio no Estado de Goiás. Anais VI Seminário Pensar Direitos Humanos. GT 3 Práticas e Representações Sociais de Promoção e Defesa dos Direitos Humanos, UFG, 2015, pp. 448-460.

SALOMÃO BARROS XIMENES é doutor em Direito do Estado (USP), professor de Direito e Políticas Públicas da Universidade Federal do ABC (UFABC), membro da Rede Escola Pública e Universidade (REPU) e coordenador do grupo de pesquisa Direito à Educação, Políticas Educacionais e Escola (DiEPEE/ UFABC). E-mail: salomao.ximenes@ufabc.edu.br

CAROLINA GABAS STUCHI é doutora em Direito do Estado (USP), professora da Universidade Federal do ABC nos cursos de Ciências e Humanidades e Políticas Públicas e no Programa de Pós-Graduação em Políticas Públicas. Email: carolina.stuchi@ufabc.edu.br

MÁRCIO ALAN MENEZES MOREIRA é mestre em Direito (UFC) e advogado do Escritório de Direitos Humanos e Assessoria Jurídica Popular Frei Tito de Alencar da Assembleia Legislativa do Estado do Ceara. E-mail: marcioalan81@ gmail.com 